\title{
Neonatal Hyperoxia and Cytochrome P450 Imprinting in Adulthood
}

\author{
YUTAKA KIKKAWA. ICHIRO FUJITA. AND RAM K. SINDHU

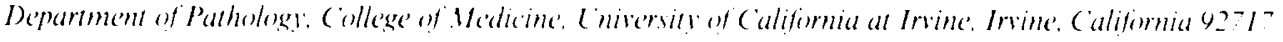

\begin{abstract}
We hypothesized that during a critical neonatal period hyperoxia may produce alterations of sexspecific cytochrome P450 isozymes in adulthood (enzyme imprinting). To test this, newborn rats were exposed to 24 or $72 \mathrm{~h}$ of hyperoxia $\left(\mathrm{O}_{2}>95 \%\right)$ within $24 \mathrm{~h}$ after birth and killed at $120 \mathrm{~d}$. In males, significant negative imprinting (decrease) was found in total cytochrome $\mathbf{P 4 5 0}$ content and male-specific CYP2C11 in the hyperoxia groups. Positive imprinting (increase) was noted in CYP1A2 and malespecific CYP3A2 in the 72-h hyperoxia group. These alterations were essentially similar when expressed on a per microsomal protein or per liver basis. In addition, the level of hepatic glucocorticoid receptor in adult male rats was elevated after neonatal hyperoxia. In females, there was a significant body and liver weight loss after hyperoxic exposure, which resulted in a negative imprinting of CYPIA2 and female-specific $2 \mathrm{C} 12$ in the 72-h hyperoxia group on a per liver basis, whereas the measured parameters were unaltered when expressed per microsome. In general, the changes were more marked with longer hyperoxic exposure, suggesting that more pronounced alterations may be induced with prolonged neonatal hyperoxia. Because hyperoxic exposure in premature neonates is a common clinical practice and decreased CYP2C11 in adult males is expected to result in feminization, we believe that the scope of this work should be expanded and eventually tested for its relevance in human subjects. (Pediatr Res 35: 255-258, 1994)
\end{abstract}

\section{Abbreviations}

P450, cytochrome P450

CYP, cytochrome P450 isozyme

Ah, aryl hydrocarbon

EROD, 7-ethoxyresorufin O-deethylase

GH, growth hormone

MSG, monosodium glutamate

PAH, polycyclic aromatic hydrocarbon

\footnotetext{
There are two lines of report that suggest that hyperoxia given during a critical neonatal period may produce permanent alterations of P450 of liver in adulthood, a condition known as enzyme imprinting (1). The first investigation involves similarity between hyperoxia and halogenated hydrocarbon or PAH administration. The demonstration from this laboratory (2), showing induction of rat hepatic CYPIA1 and $1 \mathrm{~A} 2$ by hyperoxia. is unusual and suggests the formation of endogenous ligand(s) for

Received for rapid publication October 6. 1993: accepted November 5.1993.

Correspondence: Y'utaka Kikkawa. M.D.. Department of Pathologs. College of Medicine. University of California at Irvine. Irvine. CA 92717.

Supported by Grant 111.-34688 of the National Institutes of Health. U. S. Public Health Service, a grant from the Air Resources Board of the State of California. and IRT 154. Tobacco-Related Disease Research Program. University of California.
}

Ah receptor by hyperoxic exposure. because an induction of these isozymes has been principally associated with Ah receptorligand interaction with PAH (3). Several PAH have been shown to induce P450 enzyme imprinting. For example. 3-methylcholanthrene given during the neonatal period results in decreased P450 content in adult female rats at $200 \mathrm{~d}$ of age (4). The second line of investigation involves P450 enzyme imprinting produced by neonatal administration of MSG, which is apparently the result of altered GH secretion (5). Because hyperoxia of neonates inhibits glutamine synthetase (6). a situation prone to increase glutamate. it was reasoned that P450 enzyme imprinting may likewise occur after neonatal exposure to hyperoxia. This hypothesis was tested with male and female rats by evaluating sexspecific P450) (primarily CYP2C11 for male and CYP2C 12 for female), hyperoxia-inducible P450 (CYP1Al and 1A2), and glucocorticoid receptors.

\section{MATERIALS AND METHODS}

Animals and treatment. Newborn male and female pups $(12 \mathrm{~h}$ old) with nursing mothers (Sprague-Dawley CD strain. viral pathogen-free) from nine litters were pooled and randomly assigned to a control. 24-h $\left(24-\mathrm{O}_{2}\right)$, or $72-\mathrm{h}\left(72-\mathrm{O}_{2}\right)$ hyperoxia group. Litter size was maintained at 10 pups [five males (mean weight $7.2 \mathrm{~g}$ ) and five females (mean weight $6.7 \mathrm{~g}$ )] per dam. The pups were housed with a dam in a Plexiglas chamber at $24-26^{\circ} \mathrm{C}$ with a continuous flow of oxygen $\left(>97 \% \mathrm{O}_{2},<0.05 \% \mathrm{CO}_{2}\right)(2)$. Dams in the hyperoxia group were exchanged daily with new dams without a decrease of the $\mathrm{O}_{2}$ concentration below $95 \%$. The pups. which were kept on a 12-h light-dark cycle, were weaned from dams at $30 \mathrm{~d}$. allowed rodent food and water ad libitum. The rats were killed after intraperitoneal sodium pentobarbital injection $(70 \mathrm{mg} / \mathrm{kg})$ at $120 \mathrm{~d}$. in accordance with the guidelines of the University of California. Irvine. The livers were removed and weighed, and microsomes were isolated (5).

Measurements of P450 e'nzl'mes and activitie's. P450 enzymes and activities were measured as described (7). Testosterone hydroxylation was assayed as described (8). using nonsaturating substrate concentration to retain the specificity of the microsomal hydroxylation pathways (6). Separation of testosterone metabolites was carried out by HPLC (Perkin-Elmer. Norwalk. CT) with a Supelcosil LC -18 reverse-phase $C_{18}$ column $(5 \mu \mathrm{m}, 150 \times$ $4.6 \mathrm{~mm}$ ) preceded by a Supelcosil LC -18 guard column (Supelco Inc., Bellefonte, PA) and a LC -235 diode array detector. After addition of methyltestosterone, the samples were extracted in dichloromethane, dried, injected, and eluted at a flow rate of 1 $\mathrm{mL} / \mathrm{min}$ with column temperature at $40^{\circ} \mathrm{C}$. A linear gradient of $100 \%$ solvent $\mathrm{A}\left(\mathrm{H}_{2} \mathrm{O}\right.$ :methanol:acetonotril, $\left.64: 35: 1\right)$ to $55 \% \mathrm{~A}$ and $45 \%$ solvent $\mathrm{B}\left(\mathrm{H}_{2} \mathrm{O}\right.$ :methanol:acetonotril. 18:80:2) was used from 0 to $29 \mathrm{~min}$. followed by a linear gradient of $45 \%$ to $100 \%$ B from 28 to $29 \mathrm{~min}$, which was held there for a total of $10 \mathrm{~min}$. and finally a linear gradient of $0 \%$ to $100 \%$ A was used from 30 to $40 \mathrm{~min}$ followed by reequilibration with $100 \% \mathrm{~A}$ for 40 to 60 min. The column eluant was monitored for radioactivity with an HP-Flo One radiochemical detector (Radiomatic Instruments 
Table 1. Ne'onatal hyperoxia on microsomal enzlmes of adult rat liver*

\begin{tabular}{ccccccc} 
& \multicolumn{3}{c}{ Male } & \multicolumn{2}{c}{ Female } \\
& Control & $24-\mathrm{O}_{2}$ & $72-\mathrm{O}_{2}$ & Control & $24-\mathrm{O}_{2}$ & $72-\mathrm{O}_{2}$ \\
\hline $\mathrm{P} 450$ & $1.166 \pm 0.081$ & $1.111 \pm 0.036$ & $1.051 \pm 0.051 \dagger$ & $0.838 \pm 0.037$ & $0.865 \pm 0.087$ & $0.801 \pm 0.090$ \\
bs & $0.569 \pm 0.033$ & $0.564 \pm 0.026$ & $0.581 \pm 0.028$ & $0.616 \pm 0.087$ & $0.587 \pm 0.049$ & $0.598 \pm 0.035$
\end{tabular}

* Values are mean $\mathrm{nmol} / \mathrm{mg}$ microsomal protein $\pm \mathrm{SD}$. $n=5$ for all groups.

+ Significantly different from the control group. $p<0.05$.

Table 2. Neonatal hyperoxia on testosterone hydroxylation in adult rat liver*

$\begin{array}{cccc} & \text { Control } & 24-\mathrm{O}_{2} & 72-\mathrm{O} z \\ 2 \alpha & 1141.5 \pm 3(00.3 & 776.1 \pm 123.7 \dagger & 759.1 \pm 142.5 \dagger \\ 16 \alpha & 1793.0 \pm 469.2 & 1145.5 \pm 178.3 \dagger & 1176.7 \pm 258.4 \dagger \\ 6 \beta & 229.0 \pm 40.4 & 260.7 \pm 46.2 & 426.4 \pm 10.8 \ddagger\end{array}$

* Values are mean pmol metabolite formed $/ \mathrm{mg}$ protein $/ \mathrm{min} \pm \mathrm{SD}$. Control, $n=4: 24-\mathrm{O}_{2}, n=5: 72-\mathrm{O}_{2}, n=4$.

+ Significantly different from the control group. $p<0.05$.

$\ddagger$ Significantly different from the control group. $p<0 .(01$.

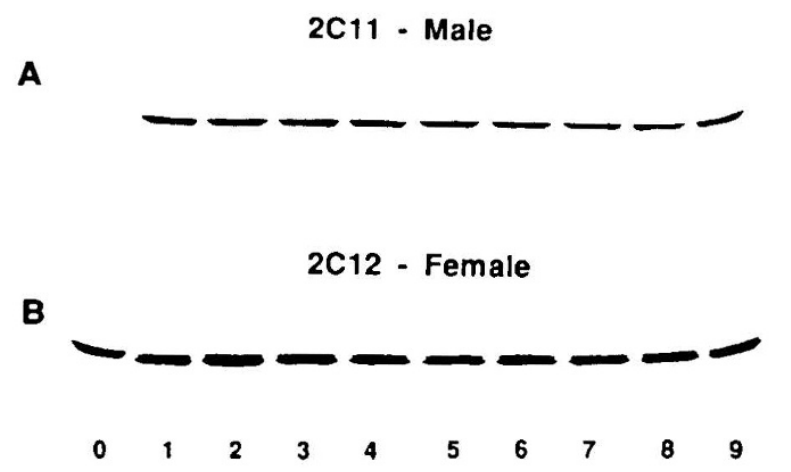

C

$2 \mathrm{C} 11$ and $2 \mathrm{C} 12$ content by densitometry

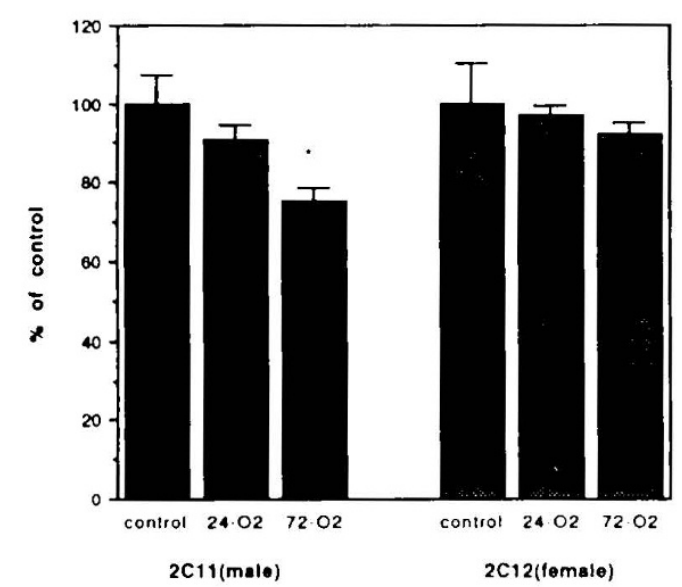

Fig. 1. Western blot analysis with anti-2C11 and anti-2C12 antibodies. A. Male rats $(120 \mathrm{~d}$ old ) that received 24 or $72 \mathrm{~h}$ of hyperoxia immediately after hirth. Each lane represents one animal. Western blot with anti-2C11 antibody shows decreased $2 \mathrm{C} 11$ for the 72-h group (lane's $7-9)$. B. Female rats $(120 \mathrm{~d}$ old $)$ with anti-2C12 antibody showing a slight tendency for decreased $2 \mathrm{C} 12$ in hyperoxic groups. $(:$ In males, the densitometric measurements of anti-2 $\mathrm{C} 11$ for the 24- $\mathrm{O}_{2}$ and the 72-O2 groups were decreased $(100 \pm 7.3 \% .90 .7 \pm 3.8 \%$, and $75.5 \pm 3 \%$ in control. 24- $\mathrm{O}_{2}$, and 72-O , respectively: ${ }^{*}, p<0.011$. In females. the densities of anti-2 212 showed a slight tendency to decrease $(100 \pm$ $10.4 \%, 97.2 \pm 2.0 \%$ and $92.3 \pm 2.6 \%$ in control. 24-O $\mathrm{O}_{2}$, and 72-O. respectively). On a per liver basis. there was a $30 \%$ decrease in the female $72-\mathrm{O}_{2}$ group $\left(100.0 \pm 5.0\right.$ is $\left.70.1 \pm 2.3^{\circ} \%, p<0.01\right)$.
Inc.. Tampa. FL) attached in tandem with HPLC and testosterone metabolites were identified with authentic standards.

Hestern hlot analisis. Polyclonal anti-CYP1A1/1A2 serum (Oxford Biochemical Research Inc., Oxford, MI), MAb 1-7-1 (anti-CYPlA1/1A2) and HyHel-9 (anti-chicken lysozyme, Dr. Park. NIH), polyclonal anti-CYP2CII and 2C12 (Dr. Imaoka. Osaka. Japan), and alkaline phosphatase-conjugated IgG (Sigma. St. Louis, MO) were used as described previously (7).

Glucocorticoid receptor hinding study: The cytosol of homogenates was treated with dextran-coated charcoal for 2-4 min at $4^{\circ} \mathrm{C}$ to remove endogenous steroids. Free and total receptor assays were carried as described (9).

Statistical analysis. Results are expressed as mean \pm SD and plotted. Statistical significance of the difference between control and $\mathrm{O}_{2}$-exposed groups was determined by one-way analysis of variance and the Dunnett's $t$ test.

\section{RESUITS}

Body: liver weight. and $P 450$ (ontent. In male rats, hyperoxia groups showed a slight tendency for body weight loss. Female rats in the $72-\mathrm{O}_{2}$ group showed an $11 \%$ decrease in body weight $(265.4 \pm 18.3$ versus $273.2 \pm 14.9 \mathrm{~g} . p<0.05, n=5)$ and a $16 \%$ decrease in liver weight $(9.02 \pm 0.96$ versus $7.55 \pm 0.79 \mathrm{~g} . p<$ $0.05, n=5$ ). Likewise, the microsomal protein content per liver was decreased by $22 \%$ in the female $72-\mathrm{O}_{2}$ group $(114.08 \pm$ 19.43 versus $88.42 \pm 15.11 \mathrm{mg} . p<0.05 . n=5$ ), although the values per gram of liver were not altered among the three groups including both males and females.

P450 content as expressed per mg microsomal protein of the male $72-\mathrm{O}_{2}$ group showed slight $(10 \%)$ but significant depression (Table $1, p<0.05$ ), whereas in females there was no change of P450.

CYP2Cll. The activity of $2 \alpha$ testosterone hydroxylase was decreased by $32 \%$ and $33 \%$ in the $24-\mathrm{O}_{2}$ and the $72-\mathrm{O}_{2}$ groups. respectively. The activity of $16 \alpha$ testosterone hydroxylase was reduced by $36 \%$ and $34 \%$ in the $24-\mathrm{O}_{2}$ and the $72-\mathrm{O}_{2}$ groups. respectively (Table 2 ).

Figure 1.A shows Western blot analyses of microsomal P450 protein from the three groups of male rats using anti-CYP2C11 antibody, which cross-reacts with CYP2C12, 2C13, and 2C6. Lane 0 is from female control rat and the main band at $49 \mathrm{kD}$ appears to represent cross-reacting CYP2C12. Lanes 1 through 9 are from male rats and are composed of dense bands of CYP2C11 (and probably 2C6) at 50 kD and light bands of CYP2C13 at $48 \mathrm{kD}$. The densities of the 24-O2 and the 72-O2 groups were $90.7 \%$ and $75.5 \%$ of the control values, respectively (Fig. 1( ). results consistent with those obtained for $2 \alpha$ and $16 \mathrm{c}$ testosterone hydroxylase activity. indicating a $25-35 \%$ decrease of CYP2C11 in the 72-O group. Male-specific CYP2C123 was unchanged among the three groups. In female rats from the three groups, there were no changes (data not shown).

('YP2C 12 . Because the substrate for $15 \beta$-hydroxylase specific for CYP2C12 is not available, we used immunoblot to characterize the changes of female-specific CYP2C12 in female rats. Anti-CYP2C12 cross-reacts with CYP2C6, 2C11, and 2C13. CYP2C 12 is shown as dense bands at $49 \mathrm{kD}$ in lanes 1 through 9. which appeared to be unaltered among control, 24- $\mathrm{O}_{2}$, and 72- $\mathrm{O}_{2}$ groups (Fig. $1 B$ ). Densitometric measurements showed a slight tendency to decrease (Fig. 1( ). Because this measurement 
Table 3. Neonatal hipheroxia on total shacoconticond receptor of adult rat liver*

$$
\begin{array}{ccc} 
& \text { Male } \\
\text { Control } & 24-0, & 72-0, \\
(n=5) & (n=4) & (n=4) \\
0.40 \pm 0.03 & 0.44 \pm 0.01+ & (0.45 \pm 0.03
\end{array}
$$
72-O2:
$(n=4)$

* Values are mean pmol ${ }^{3} \mathrm{H}$-dexamethasone bound/mg protein \pm SD.

+ Significantly different from the control group. $p<0.05$.

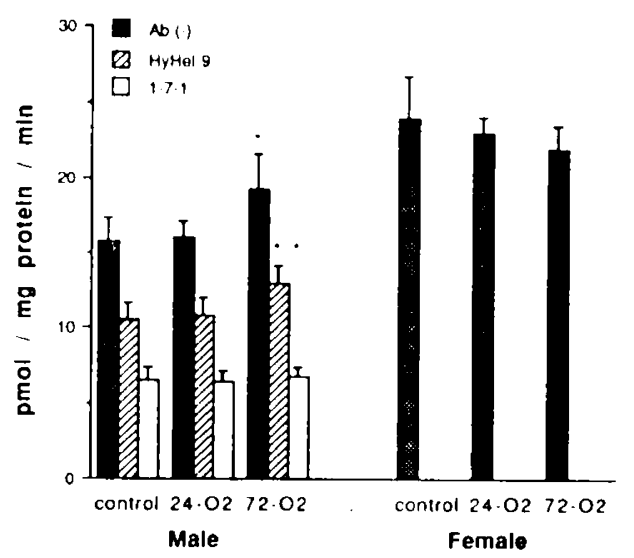

Fig. 2. Neonatal hyperoxia and EROD activity in the adult. leff pancl. In males. FROD was significantly increased with $1^{* *}, p<0.01$. HyHe 1-9: $10.57 \pm 1.18$ is $13.05 \pm 1.13 \mathrm{pmol} / \mathrm{mg}$ of microsomal protein) or without $\left[{ }^{*}, p<0.05 . \mathrm{Ab}(-)\right]$ nonspecific antibody in the 72-0) group. The 1-7-1 antibody abolished a significant difference in the EROD activity of control and 72-Oz groups. Righth panel. In females, there was a slight tendency for EROD activity per microsome to decrease in hyperoxia groups. There was. however, a significant decrease in EROD activity per liver $(19.35 \pm 320$ is $2731 \pm 466$ pmol. $p<0.01)$.

is based on microsomal protein, we calculated the values per liver, which showed a decrease of $30 \%$ in the 72-O group $(p<$ 0.01 ). The light bands above CYP2C12 at $50 \mathrm{kD}$ probably represent $C Y P 2 C 6$. In males, this band represents a combination of 2C6 and 2C11, shown in lane 0. Thus, these studies demonstrate that CYP2C12 decreased in female rats on a per liver basis after neonatal exposure to hyperoxia. In male rats from three groups, the results were identical with that shown in lane 0 of Figure $1 B$ and showed no changes among the three groups (data not shown).

('YP3.12. Testosterone $6 \beta$ hydroxylase activity, representing male-specific CYP3A2, increased almost 2-fold in male rats of the $72-\mathrm{O}_{2}$ group (Table 2).

Glucocorticoid receptor. The total number of glucocorticoid receptors increased by $10 \%$ in the 24-O group in the males $(p$ $<0.05)$ and increased further $\left(12.5 \%\right.$ ) in the $72-\mathrm{O}_{2}$ group compared with the controls, the latter showing large individual variations (Table 3). In the females, there was a tendency for increase in the hyperoxia groups. These results are similar to those of hypophysectomy in males and females.

CYPl. $1 / 1.12$. In males, EROD activity was significantly increased in the $72-\mathrm{O}_{2}$ group $(p<0.01$, Fig. 2), which was similar to HyHel-9 (nonspecific antibody control). MAb 1-7-1 abolished a significant difference in the EROD activity of control and $72-\mathrm{O}_{2}$ groups in male rats. indicating that the increased EROD activity was likely due to an increase in CYPIAl/1A2. Although in female rats there was no significant difference between control and hyperoxia groups per $\mathrm{mg}$ microsomal protein. there was a significant decrease of EROD activity per liver (2731 \pm 466 versus $1935 \pm 320$ pmol, $p<0.01)$.

CYP1A2 protein $(53 \mathrm{kD})$, as identified in our previous study (7), was seen as the major band for control, 24- $\mathrm{O}_{2}$, and 72-O2 groups (Fig. 3.4 and $B$ ). Light bands below CYPIA2 protein are probably a degradative product of $1 \mathrm{~A} 2(10)$. In males. CYPIA2

$$
\begin{array}{ccc} 
& \text { Female } \\
\text { Control } & 24-0, & 72-0 . \\
(n=5) & (n=5) & (n=5) \\
0.35 \pm 0.04 & (0.40 \pm 0.05 & 0.39 \pm 0.05
\end{array}
$$

$1 \mathrm{A2}$ - Male

A

$1 \mathrm{A2}$ - Female
B

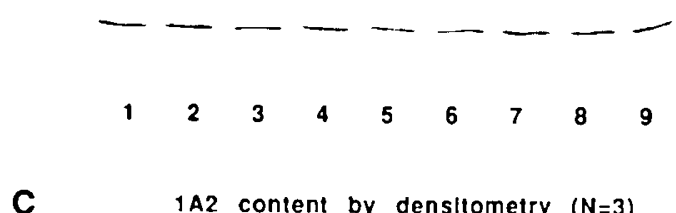

C

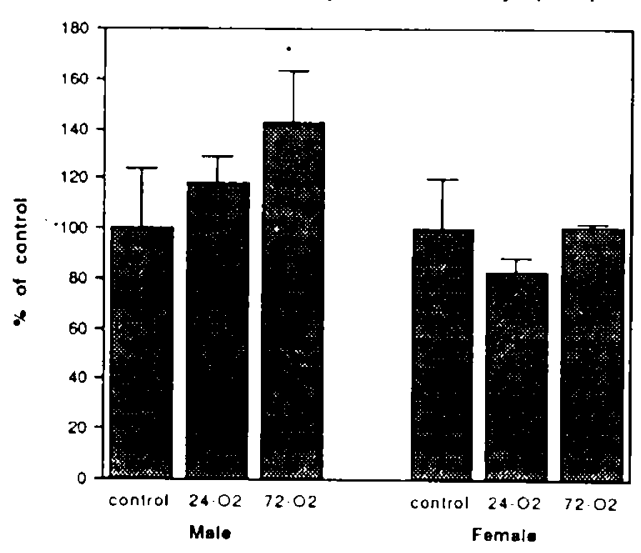

Fig. 3. Western blot analysis with anti-1 12 antibody. 1 In males with polyclonal anti- $\mathrm{A} 1 / 1 \mathrm{~A} 2$ antibody showing $1 \mathrm{~A} 2$ protein, the major bands are denser in the 72-O2 group (lemes $\left.{ }^{-}-4\right)$ compared with those of controls (lames $1-3$ ). B. In females. 1 A2 proteins were unaltered among the three groups. $(\therefore$ In males, the densitometric measurements for the 72-O: group showed a $42 \%$ increase wer the control value $(100.0 \pm$ $23 . x^{\prime \prime}$ in $\left.1+2.2 \pm 21.3 \%:{ }^{*}, p<0.05\right)$. In females, there were no changes.

protein bands were denser in the 72-O 2 group compared with those in the controls and showed a $42^{\prime \prime}$ increase over the control value by densitometric measurements $(p<0.0)$. Fig. 3( $)$. A small increment in $|\mathrm{A}|$ protein could have been missed in this study because of the very low constitutive level of CYPIAl. In females, CYPIA2 proteins were unaltered among the three groups (Fig. $3 B$ and ('). These results are consistent with the values of EROD activity shown in Figure 2 and show increased CYPIA 2 in males after neonatal hyperoxia. the only documented enzyme imprinting involving this subfamily of $\mathrm{P} 450$ to date.

\section{DISCIISSION}

The results presented here show that neonatal hyperoxia of 24 or $72 \mathrm{~h}$ duration altered the profiles of $\mathrm{P} 450$ in adult rats in a gender-differentiated manner. The 12()-d interval between oxygen exposure and the observed effects is consistent with lifelong changes in the regulation of these enzymes (enzyme imprinting) There was a general trend for the 72-h exposure group to show more pronounced alterations than those seen in the 24-h exposure group. indicating the need for further examination of dose. 
response of the measured parameters with the hyperoxic exposure of varied concentration and duration.

In rats. P450 exhibit a high degree of sex specificity. Sexspecific P450 for males include CYP2C11, 2C13, 2A2, and 3A2 and for females, CYP2C12 and 2A1. Enzyme imprinting of P450 has been demonstrated primarily in sex-specific P450, as observed after exposure to estrogenic or androgenic compounds (1), neonatal castration (1). MSG administration (5), and exposure to xenobiotics (4). Many studies have demonstrated that the characteristic gender-specific pattern of $\mathrm{GH}$ secretion is of prime importance in the expression of male- or female-specific P450 isozymes (1). which may be one of the targets of androgen imprinting for sexual differentiation occurring during a critical neonatal period (1). Neonatal castration results in a decrease in CYP2C11 and an increase in CYP2C12 in adult male rats (1). By depleting GH-releasing factor through destruction of arcuate nucleus of hypothalamus. MSG treatment of neonates produced a decrease in male-specific CYP2C11, 3A2, and 2A2 and an increase in female-specific CYP2AI in adult male rats (11). In both instances, the patterns of $\mathrm{P} 450$ isozyme changes are significantly different from the results of the current study. Hypophysectomy of adult male rats showed a decrease in CYP2C11, an increase in CYP3A2 $(1,11)$, and an increase in glucocorticoid receptor (12), a pattern similar to that seen in the male rats in current investigation. In female rats, hypophysectomy results in a decrease in CYP2C12 (11). Our results, showing a decrease of this isozyme expressed per microsome. a denominator used in other published studies, may ultimately become significant if hyperoxic exposure is prolonged. Thus, the altered profiles in both males and females in this study are similar to the acute effects of hypophysectomy. It remains to be seen that the changes of P450 isozymes seen in this study are indeed a manifestation of pituitary pathology. Similarly, the relationship between the current observation and a karyorrhexis of the pontosubicular region of brains seen after neonatal hyperoxic exposure (13) needs to be defined. The neonatal rats exposed to $100 \%$ oxygen for $2 \mathrm{~h}$ demonstrated decreased glutamine synthetase activity of brain (6). which is expected to cause an accumulation of glutamate, a situation similar to that with MSG administration. Such a mechanism may also contribute to the development of the observed effects in the current study. The pathogenetic mechanism, however, may be more complex than the hypothalamopituitary involvement: we showed that neonatal hyperoxia produced permanent up-regulation of CYP1A2 in the liver. Assuming that an induction of CYPIA1/1A2 by hyperoxia is mediated through Ah receptors as in PAH (3), the increased glucocorticoid receptor level seen in this study may be mediated through demonstrated structural homology between a xenobiotic-responsive element of CYP1Al gene and a glucocorticoid-responsive element of the glucocorticoid receptor gene (14): both elements promote transcription of their respective gene products. Furthermore, changes in sex steroids occurring secondary to the altera- tions of sex-specific P450 isozymes may likewise contribute to the ultimate outcome.

Whatever the mechanism may be. a long-lasting decrease in CYP2C11 may be expected to feminize the male rats because the level of estradiol may have been elevated in these rats for several reasons: androgens are normally deactivated by hydroxylation by CYP2C11, and decreased CYP2C11 and a subsequent reduction of hepatic clearance of androgens may produce excess estrogen through extrahepatic aromatization of surplus androgens (15). In addition, CYP2C 11 plays an important role in the deactivation of estrogens via $16(x$-hydroxylation and catechol formation (15). Down-regulation of CYP2C11 is expected to facilitate the accumulation of estradiol. Furthermore, an increased level of estradiol may create a vicious cycle because it has been established that estradiol interacts with hypothalamic receptors and modifies the release of neuroendocrine factors including somatostatin and GH-releasing factor (15) and thus down-regulates CYP2C11.

\section{RIFHRENCES}

1. Waxman DJ 1988 Interactions of hepatic cytochromes P450 with steroid hormones Biochem Pharmacol 37.71-84

2. Okamoto T. Mitsuhashi M. Fujita I. Sindhu RK. Kikkawa Y 1993 Induction of eytechrome P450 IAI and IAZ by hyperoxia. Biochem Biophys Res Commun (in press)

3. Nebert DW. (ionzalez FJ 1987 P450 genes: structure. evolution, and regulation. Annu Rev Biochem 56:945-993

4. Bagley DM. Haves JR 1985 Xenobiotic imprinting of hepatic metabolic enzyme systems: effect of neonatal 3-methylcholanthrenc administration. Biochem Pharmacol 34:2569-2573

5. Shapiro BH. MacLeod JN. Pampori NA. Morrissey JJ. I apenson DP. Waxman DJ 1989 Signalling elements in the ultradian rhythm of circulating growth hormone regulating expression of sex-dependent forms of hepatic eytochrome P450). Endocrinology 125:2935-2944

6. Schor NF. Ahdab-Barmada M. Nemoto E 1991 Brain glutamine synthetase activity and hyperoxia in rats. Brains Res $566: 342-34.3$

7. Sakai H. Okamoto I, Yamamoto R. Sindhu RK. Kikkawa Y 1992 Suppressive effect of interleukin-1 on pulmonary cytochrome $\mathrm{P} 450$ and superoxide anion production. Biochem Biophys Res Commun 185:1083-1090

8. Waxman DJ 1991 Rat hepatic P450lla and P450IIC subfamily expression using catalytic, immunochemical, and molecular probes. Methods Enzymol 2() $6: 249-267$

y. Shirwany TA. Hubhard JR, Kalimi M 1986 Gilucocorticoid regulation of hepatic cytosolic glucocorticoid receptors in vio and its relationship to induction of tyrosine aminotransferase. Biochim Biophys Acta 162:162-168

10. Mvers MJ. Liu G. Miller H. Gelboin HV. Robinson RC. Friedman FK 1990 Synthetic peptide antigens elicit monoclonal antibodies to cylochrome P450) IA2. Biochem Biophys Res (ommun 169:171-176

11. Waxman DJ. Morrissey JJ, MacLeod JN. Shapiro BH 1990 Depletion of serum growth hormone in adult female rats hy neonatal monosodium glutamate treatment without loss of female-specific hepatic enzyme P450) 2d(IIC12) and steroid 5 (r-reductase. Endocrinology $126: 712-720$

12. Yarney TA. Kendall JZ, Randall (;CB 1990 C Cytosolic glucocorticoid receptors in the porcine lung during development and after hypophysectomy or thyroidectomy. J Fndocrinol 127:341-344

13. Ahdah-Barmada M. Moossy J. Nemoto EM. Lin MR 1986 Hyperoxia produces neuronal necrosis in the rat. J Neuropath Exp Neurol 45:233-246

14. Fujisawa-Sehara A. Sogawa K. Yamane M. Fuji-kurivama Y 1487 Characterization of xenobiotic responsive elements upstream from the drug metabolizing cytochrome P-450 gene: a similarity of glucocorticoid regulatory elements. Nucleic Acids Res 15:4179-4191

15. Murray M. Cantrill E. Mehta I. Farrell (iC 1992 Impaired expression of microsomal evtochrome $\mathrm{P} 4502 \mathrm{C} 11$ in choline-deficient rat liver during the development of cirrhosis. J Pharmacol Exp Ther 261:373-380 